\title{
Students' Social, Emotional and Intercultural Competencies and their Development in School Settings
}

\author{
Mirta Mornar, Institute for Social Research in Zagreb, Croatia \\ Jelena Matić Bojić, Institute for Social Research in Zagreb, Croatia \\ Iva Odak, Institute for Social Research in Zagreb, Croatia \\ Nina Eliasson, Mid Sweden University, Sweden
}

Katinka Gøtzsche, The Danish Association for Promoting Life Wisdom in Children,

Denmark

Lana Jurko, Network of Education Policy Centers (NEPC)

Ana Kozina, Educational Research Institute, Slovenia

Aleš Ojsteršek, Ministry of Education, Science and Sport, Slovenia

Christine Sälzer, University of Stuttgart, Germany

Manja Veldin, Educational Research Institute, Slovenia

Svenja Vieluf, Leibniz Institute for Research and Information in Education, Germany

\section{Introduction}

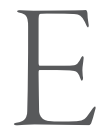

xisting research on students' competencies and their educational experiences points to social and emotional competencies as being crucial for students' well-being and academic performance, and for establishing satisfactory relationships with others. These findings stress the importance of the role of the school in fostering not only students' cognitive development, but their social and emotional development as well. School-based programmes for students' social and emotional learning (SEL) hold the potential to provide "the missing piece" in education (Bridgeland, Bruce and Hariharan, 2013), thus providing students with the skills needed for personal development and fostering harmonious social relations.

Social and emotional learning includes processes of acquiring core competencies to recognise and manage emotions, set and achieve positive goals, appreciate the perspectives of others, establish and maintain positive relationships, make responsible decisions, and handle interpersonal situations constructively (Elias et al., 1997). According to the widely used conceptual framework, SEL programmes aim to foster the development of five interrelated sets of cognitive, affective and behavioural competencies: self-awareness, self-management, social awareness, relationship skills, and responsible decision-making (Collaborative for Academic, Social, and Emotional Learning (CASEL), 2003). In other words, SEL programmes aim to build children's capacities to accept and value themselves 
and others, handle interpersonal situations effectively and build lasting and meaningful relationships.

SEL-related skills can be taught through systematic instruction, by practising and applying them to different situations with the ultimate goal of students using them as part of their regular repertoire of behaviours (Ladd and Mize, 1983), and by establishing safe, caring learning environments and improving the school climate (Cook et al., 1999). Further, many programmes support students in developing social and emotional competencies in preventing specific problem and risk behaviours like substance abuse, violence, bullying and academic failure (Zins and Elias, 2006). It is likely that the combination of improvements in students' social and emotional competencies, the school environment, teacher practices and expectations, and student-teacher relationships contribute the most to student outcomes related to SEL and characterise the most effective SEL programmes (Catalano et al., 2002).

Aside from social and emotional competencies, there is rising awareness of the importance of intercultural competencies as they become ever more important in today's society. Intercultural competencies encompass the knowledge, skills and attitudes needed to communicate effectively and appropriately with people from other cultures. "The development of such attitudes, knowledge and skills implies an ongoing learning process that involves interpretation, self-reflection and negotiation, which gradually transform one's attitude, knowledge and skills towards cultural differences" (Hernández-Bravo, Cardona-Moltó, and Hernández-Bravo, 2017, p. 2I). Although intercultural competencies include skills related to both social and emotional competencies, they cannot be reduced solely to social and emotional skills or developed through traditional SEL programmes. The reason for that lies in the fact that the relationships between social and cultural groups are generally influenced by the socio-historical context, as well by differences in the groups' power, social status and collective experience (Auernheimer, 2003; Leiprecht, 200I). Therefore, social and emotional learning must take account of specific knowledge concerning other cultures, as well as tackle deeply ingrained obstacles to intergroup communication, such as social inequality and discrimination, so as to be adjusted to the needs of contemporary society (Jugović, Puzić and Mornar, 2020). Namely, social and emotional learning must be accompanied by the development of intercultural sensitivity and intercultural competencies.

The present article aims to review and reflect on several important issues in social, emotional and intercultural learning, juxtaposing the development of intercultural competencies with the development of social 
and emotional competencies. A literature review has been conducted as a part of the Erasmus+ project "HAND in HAND: Social and Emotional Skills for Tolerant and Non-discriminative Societies (A Whole School Approach)". The project centred around designing and evaluating schoolbased interventions for developing social, emotional and intercultural competencies of students, teachers and school staff in five countries across Europe (Croatia, Denmark, Germany, Slovenia and Sweden), aimed at fostering more inclusive school environments. The HAND in HAND project is the first, to the best of our knowledge, to integrate social and emotional competencies with intercultural competencies, providing both a theoretical and practical contribution to social, emotional and intercultural (SEI) learning. The literature review presented in this article was used to guide the development of the HAND in HAND programme for developing students' SEI competencies (Marušić et al., 2020) and resulted in a review catalogue of SEI programmes for students (Marušić et al., 2017). The catalogue represents an overview of evidence-based SEI programmes for students, and is divided into two sections: international catalogue, including descriptions of international SEI programmes and national catalogues, containing a summary of SEI programmes in the countries participating in the project. It is important to note here that the purpose of this article was not to conduct a systematic review of SEI learning nor SEI programmes (for meta-analyses of existing SEL programmes and their effects, see Durlak et al., 2011 and Taylor et al., 2017), but to inform the development of new SEI programmes by examining existing ones and building upon their theoretical backgrounds, activities and evaluations. Accordingly, the literature search was conducted using the following keywords and their synonyms, as well as combinations: programme, students, social-emotional learning, self-awareness, self-management, social awareness, relationship skills, responsible decision making, intercultural learning. Since the HAND in HAND programme is intended for students at the lower secondary school level, programmes and challenges pertinent roughly to this age group were included in the review.

The ultimate goal of all programmes presented in the catalogue was the same - to promote the positive development and well-being of students through school-based interventions. However, the approaches used to teach SEI competencies vary greatly depending on the programme, as well as the programme's content and its design. For this reason, one of this article's aims was to address the question of how SEI competencies are taught, with particular emphasis on the content and theoretical background of existing interventions and/or programmes, as well as their methodological and organisational aspects. 
Not all SEI interventions and programmes are equally well received and successful; along with the content of a programme, its implementation is crucial. Yet, their evaluation is often scarce or inconclusive, making it difficult to distinguish more successful programmes from others. In the current article, we explore whether and how the evaluation of existing programmes has been conducted, the most important results and the aspects of implementation which, according to programme evaluations, are key to fostering the development of social, emotional and intercultural competencies in adolescents.

Before we proceed to explore the existing social, emotional and intercultural learning programmes, a brief overview of the theoretical and empirical grounds of the development of social, emotional and intercultural competencies is given.

\section{On the importance of students' social, emotional and intercultural competencies}

According to the widely used CASEL (2003) model, social and emotional competencies include the following dimensions: self-awareness, self-management, social awareness, relationship skills and responsible decision-making. In this context, self-awareness and self-management can be viewed as primarily emotional competencies and social awareness and relationship skills as primarily social competencies, whereas responsible decision-making represents a competence that may be considered to be both social and emotional. As defined within CASEL (2003), self-awareness includes the ability to accurately recognise one's emotions and thoughts and their influence on behaviour, as well as to accurately assess one's strengths and limitations while having a well-grounded sense of confidence and optimism. Complementarily, self-management includes the ability to regulate one's emotions, thoughts and behaviours effectively in different situations. This includes managing stress, controlling impulses, motivating oneself, as well as setting and working toward personal and academic goals. Social awareness involves the ability to take the perspective of others and empathise with others from diverse backgrounds and cultures, to understand social and ethical norms for behaviour, and to recognise family, school and community resources and supports. Relationship skills include the ability to establish and maintain healthy and rewarding relationships with various individuals and groups, communicating clearly, listening actively, cooperating, resisting inappropriate social pressure, negotiating conflict constructively, and seeking and offering help when needed. While integrating social and emotional competencies, responsible decision-making includes the ability to make constructive and respectful 
choices about personal behaviour and social interactions based on a consideration of ethical standards, safety concerns, social norms, the realistic evaluation of the consequences of various actions, and the well-being of self and others (Bridgeland, Bruce and Hariharan, 2013).

With respect to (empirical) evidence, more than 500 evaluations of various SEL programmes can be found in the literature (Weissberg et al., 2015). Most programmes involve school-based interventions, but one can also find programmes that extend beyond the school context, including parents and after-school programmes. Two large meta-analyses provided evidence of the positive effects of programmes for the social and emotional learning for students' well-being, attitudes about self, others, and school, and other positive outcomes. Results of a meta-analysis by Durlak et al. (2011) indicate that students who were included in school-based universal intervention programmes for social and emotional learning demonstrated enhanced social and emotional skills, attitudes, and positive social behaviours following intervention compared to students not included in such programmes. Students who participated in SEL intervention programmes also showed fewer behavioural problems and lower levels of emotional distress. Further, SEL interventions have also had a significant impact on the students' academic performance. A more recent meta-analysis (Taylor et al., 2017) also shows that students who participated in SEL programmes demonstrated better results in social and emotional skills, attitudes, and other indicators of well-being, compared to students in the control group, even in follow-up measurements 6 months to 18 years post intervention. Benefits were similar regardless of the students' race, socioeconomic background, or school location, revealing the universal nature of the relevance of social and emotional skills for students' well-being.

We argue that the development of intercultural competencies and intercultural understanding can also be conceptualised as being built on the grounds of the CASEL (2003) model, by e.g. being aware of and regulating one's emotions (prejudice), thoughts (stereotypes) and behaviour (discrimination), as well as by taking the perspective of and empathising with others from diverse backgrounds. However, intercultural competencies also include important elements that stem outside the domain of social and emotional competencies, and outside of the CASEL (2003) model. One of these is the critical dimension, which acknowledges how established social and mental structures (Bourdieu, 1984) shape our current behaviour. The critical dimension's importance is supported by reviews of emerging school-based approaches for developing students' intercultural understanding (Walton, Priest and Paradies, 2013). According to this line of research (Zirkel, 2008), long-term changes in attitudes and 
behaviours require that students and teachers explicitly address and discuss different positions towards cultural diversity, which include exploring students' attitudes towards ethnicity, race and culture. In doing so, students must develop a critical framework to think about differences and reflect on their own cultural identity. Without such a framework, approaches for developing students' intercultural understanding tend to be less effective since students tend to dismiss alternative experiences due to holding onto the attitudes of their own cultural groups. The development of intercultural competencies and intercultural understanding may be described as 'an on-going critically reflexive process' concerning the progressive development of the knowledge, skills and attitudes that may be needed to interact across social and cultural groups (Walton et al., 20I3, p. I8I). Such theoretical positioning corresponds with the CASEL model since it involves the development of cognitive, emotional and interpersonal skills, as well as the critical social and cultural-awareness and self-awareness.

One central point in developing intercultural competencies is that a better understanding of 'other' people enhances understanding of one's own culture and identity. In other words, critical intercultural understanding involves an on-going process of self-reflection in which the perception one has of their identity is constantly being (re)defined in relationships with 'others' (Gundara, 2000). From an educational standpoint, the development of students' intercultural competencies implies the possibility of affirming the identities of deprivileged social and cultural groups while at the same time undermining young people's ethnocentric attitudes. The anticipated result of intercultural learning should be the reduction of xenophobia and discrimination (Katunarić, 1994), the development of students' intercultural sensitivity (Bennett, 2004), along with more generally preparing young people for life in culturally diverse societies (Luchtenberg, 2005).

Next, we summarise the results of our review regarding the content and background of SEI interventions, their methodological and organisational aspects, and their effectiveness.

\section{Teaching SEI competencies: Content and background of the SEI interventions}

Over the last few decades, a growing number of programmes have aimed to develop social and emotional competencies in children and adolescents. However, in their review of the field of social and emotional learning, Brackett, Elbertson and Rivers (2015) revealed that no individual overall or leading theory is able to explain SEL. Instead, different aspects of one particular programme may be based on a single theory, while other 
programmes might rely on multiple theories. This implies that the theoretical frameworks guiding the development of existing programmes tend to be fragmented and diverse, requiring further refinement and comprehension. Moreover, intercultural competencies have so far not been included in SEL programmes, although a rising number of interventions have sought to foster these disparate, yet related competencies, thereby requiring integration and conceptualisation on the SEI level.

Evidence reviews of effective school-based interventions conducted by leading researchers in the field suggest that a key characteristic of an effective SEL programme is that it has a strong basis in theory (Weissberg, Resnik, Payton, and O'Brien, 2003). Simultaneous to this, the theoretical framework guiding existing programmes is not always clear. While reviewing the programmes, we noticed that universal school-based social, emotional and intercultural learning programmes which mention their rationale as for programme development, design and implementation are founded on a variety of theoretical approaches, such as: child development and neuroscience (Anderson, Weimer and Fuhs, 2020), bioecological systems theory and ecocultural theory (Garner et al., 20I4), temperament theory (McCormick et al., 2015), mindfulness theory (Schonert-Reichl et al., 2015) and incremental theory of personality (Yeager, 2017), to name a few.

According to Sklad et al. (2012), most programmes cite social learning theory (Bandura and Walters, 1977) as the foundation for their activities and goal achievement, while Brackett, Elbertson and Rivers (2015) categorise relevant theories that may be useful for SEL content development and implementation strategies into: systems theories, learning theories, child development theories, theories of information processing, and theories of behaviour change. All of the above-mentioned theories are relevant for certain aspects of social, emotional and intercultural learning, and worth considering while developing or adapting SEI programmes. Still, significant thought must be put into determining which theories are appropriate for which aims and how their insights can be applied to different elements of the programme.

The development of intercultural competencies builds on social and emotional competencies (e.g. self-awareness, social awareness, empathy), expanding them to a wider context and directing them to concepts like stereotypes and prejudice, which can inhibit or impede intergroup communication (Leiprecht, 200I), as well as individual communication between people of different cultures. Moreover, developing intercultural competencies cannot be reduced to simply "learning about other cultures" (Auernheimer, 2003). It instead needs to be seen as context-dependent, 
and involve a critical dimension which will allow students to become aware of the role culture plays when it comes to differences in power or social status, while bearing in mind the foundations of social and emotional competencies required to interact with others.

Despite the theoretical diversity among existing programmes, there seems to be a consensus on their aims - to foster children's better understanding of themselves and others, and to support them in dealing with challenges in their daily life related to their emotions and relationships. Further, researchers have noted that learning and education take place in the context of relationships and that similar risk factors are responsible for various mental health and behaviour problems, such as substance abuse, aggression and violence (Payton et al., 2000), which calls for the integration of different theories in order to achieve the aims of SEI learning. As noted by Weissberg, Kumpfer and Seligman (2003), preventing problems and promoting positive outcomes in the context of prevention requires integrating theoretical frameworks and intervention strategies of prevention science (Coie et al., 1993; Mrazek and Haggerty, 1994; Reiss and Price, 1996) with those of various fields like positive psychology (Seligman and Csikszentmihalyi, 2000), applied developmental science (Hetherington, 1998; Lerner, Fisher and Weinberg, 2000), competence enhancement (Masten and Coatsworth, 1998; Weissberg and Greenberg, 1998), health promotion (Marx and Wooley, 1998; Perry, 1999), positive youth development (Catalano et al., 2002; Larson, 2000; Pittman et al, 200I), resilience (Glantz and Johnson, 1999) and well-being (Cowen, 1983).

Aspiring to anchor their programmes in a comprehensive framework, most developers of existing programmes cite the CASEL conceptual framework, which targets a combination of behaviours, emotions and cognitions, and posits that prevention can be achieved through the enhancement of social and emotional competencies: self-awareness, self-management, social awareness, relationship skills and responsible decision-making (Greenberg et al., 2003). This framework has become widely used in the last two decades, encompassing the relevant skills required to successfully navigate through the social and emotional challenges of contemporary life.

In addition, our review of existing evidence-based programmes and interventions reveals that existing interventions vary greatly in terms of their content and the activities used to achieve their aims. In this respect, the programme content focused on social and emotional competencies includes topics as wide as the following: development of relational competence, mental health promotion, social skills training, empathy development, creating a safe school climate, bullying and substance use 
prevention, positive youth development and integration of LGBT youth. Meanwhile, programmes focused on intercultural competencies target the development of intercultural values, constructive conflict resolution, perspective-taking, openness to other cultures, acceptance of students with different religious and ethnic backgrounds, prejudice reduction and the development of a multicultural school environment.

It may be argued that these disparate competencies (i.e. social and emotional, and intercultural) go hand in hand - it is difficult to imagine intercultural competencies without social and emotional competencies and, in certain contexts, vice versa. For example, perspective-taking, which is taught as part of intercultural competencies, is an integral part of empathy - its cognitive component. Yet, empathy and understanding of how others feel is taught as a key aspect of social and emotional competencies. There are many examples of such overlaps between approaches aimed at developing either social and emotional or intercultural competencies. For this reason, we propose that these two approaches should be integrated while developing new programmes or adapting existing ones, and that the activities included in these programmes reflect their SEI nature.

\section{Teaching SEI competencies: Methodological and organisational aspects}

In this section, we describe some of the primary organisational and methodological aspects of the existing programmes and interventions. We were interested in who the participants were, their age, how the programmes were structured, who the actors involved in the programme were, the methods and duration of the programme interventions, as well as the type of lesson materials used during programmes in schools. Our literature review of programmes which aim to develop and enhance students' SEI competencies indicates that children and young people of all ages are target populations for the interventions. Programmes start as early as kindergarten (e.g. McCormick et al., 2015), but most are implemented in lower and upper secondary education (e.g. Berger, Brenick and Tarrasch, 2018; Berry et al., 2016; Schonert-Reichl and Stewart Lawlor, 2010). Aboud et al. (2012, p. 308) emphasise that, for intercultural competence programmes, "there is still debate as to whether programs should be targeted at an early age when prejudice is quickly developing or in middle childhood when prejudice diverges due to environmental input" (Raabe and Beelmann, 20II).

The programmes were generally set as randomised controlled trials, thus enabling testing of the intervention's effectiveness. The programme's structure usually includes self-report questionnaires completed by the 
students before and at the end of the intervention. In some cases, this is also paralleled by before and after questionnaires filled in by the teachers. Pupils are typically divided into control and experimental groups in order to allow the testing of programme effects. When gender-mixed classrooms are involved, which is mostly the case, the programmes tended to include pupils approximately evenly divided by gender. Like the pupils, teachers selected for participation in the programmes are also usually divided into two groups - one group of teachers actively participating in the programme, and the other being the control group.

As for the school selection for a programme's implementation, programme leaders and researchers tend to sample schools with similar socio-economic backgrounds (e.g. Berger et al., 2018) or, with a larger sample, the sample of schools tends to reflect the variety in the population - "schools in which students were recruited were representative of a diverse range of socioeconomic status and were considered to be a microcosm of the larger society" (Schonert-Reichl and Stewart Lawlor, 2010, p. I4I).

Programmes for pupils also vary in the actors included in the programme implementation. Programme leaders in school settings were predominantly classroom teachers, who had usually received some kind of programme training before implementing the programme in school (e.g. Kelly et al., 2004; PATHS and CASEL programmes). Some programmes in schools were led by non-classroom teachers (e.g., Mendelson et al., 2010; Napoli, Krech and Holley, 2005, in: Gueldner and Feuerborn, 2016), while others were delivered by a trained psychologist (e.g. Coelho et al., 2017) or a visiting counsellor, often by a researcher who was the project leader (e.g. Yamamoto, Matsumoto and Bernard, 2017). Some projects led by school teachers had support by way of periodical school visits by facilitators, coach consultants or supervisors of the programme (e.g. McCormick et al., 2015; Berry et al., 2016). Parents were also included in programmes to various extents, with some only giving parental/guardian consent for the pupils, and others engaging more intensively as they underwent a brief education on social and emotional competencies (e.g. INSIGHTS programme, McCormick et al., 2015).

Programmes also vary in their duration, i.e. the timespan of the whole school intervention, intervals between interventions, and the duration of one programme lesson/intervention. Some programmes were implemented over 2 academic years (e.g. Berry et al., 2016; Coelho at al., 2017; McCormick et al., 2015), while others covered a more limited timeframe, delivering from 5 to 25 sessions, often held weekly, rarely bi-monthly (e.g. 
Berger et al., 2016). Sessions lasted from 30 to 50 minutes on average, depending on the pupils' age and duration of the school class.

The programme leaders, whether they are teachers, researchers or psychologists, employed a variety of methods and learning materials in the classroom in order to gain pupils' attention and enhance their understanding of the topics. Curriculum materials included puppets, workbooks, flash cards, handouts and videotaped vignettes (McCormick et al., 2015). Lesson materials also included teacher scripts, activity sheets, pictures, photographs and posters (Berry et al., 2016), as well as mindmaps, small group discussions, writing one's stories and drawing cartoons (Liebkind et al., 2014). Lessons typically consisted of individual activities, group activities, and overall class activities to ensure students' sustained concentration and interest in the materials (Yamamoto, Matsumoto and Bernard, 2017). Regarding intercultural programmes, initial teacher training also included explanations, modelling and role-playing of a complete lesson by the school counsellor (Hernández-Bravo, Cardona-Moltó and Hernández-Bravo, 2017), to be applied in the classroom, i.e. with students.

Intercultural programmes also differ in their approach to the selection of participants as programmes are sometimes implemented in ethnically or culturally homogeneous settings and some target multicultural or otherwise mixed school settings (e.g. Hernández-Bravo, Cardona-Moltó and Hernández-Bravo, 2017). Likewise, they differ in the approach to intergroup contact since it is possible to differentiate programmes with direct intergroup contact between the pupils from educational settings based on indirect contact (vicarious contact, extended contact, imagined contact - Di Bernardo et al., 2017). According to Berger et al. (2016, p. 3), "the first group of interventions conducted among children in peaceful multicultural societies are derived from intergroup contact theory (Allport, 1954; Pettigrew et al., 2011) and include programs that entail direct contact (i.e., face-to-face contact) and others that promote indirect contact (i.e., contact that is not face-to-face)".

We conclude that SEI programmes encompass participants of all ages, are mainly based in school settings, and involve school staff in an active way, especially teachers. The programmes tend to last at least 5 sessions or longer, preferably throughout I or more school years. For programmes dealing with the topic of SEI competencies, it is important to have educated school personnel sensitive to the themes in order to ensure a stronger impact on students and their better communication with teachers. Many programmes applied by teachers in schools had the active support of researchers, project counsellors, psychologists or other professionals whose expertise was related to SEI competencies. On these grounds, 
we recommend that the subsequent delivery of similar programmes tackling the SEI competencies of students follows the practice of including as many school staff and outside support as required in order to attain overall better programme impact and sustainability.

\section{Effectiveness of social, emotional and intercultural learning programmes}

In the previous sections, we reviewed common features of social, emotional and intercultural programmes aimed at developing students' social, emotional and intercultural competencies. The quality of implementation of SEI programmes for students depends, however, not only on the quality of the programmes themselves, but on the characteristics of the context in which the programmes are being implemented. On both the micro and macro levels, one finds factors that may promote/hinder the effectiveness of SEI programmes, i.e. the development of students' SEI competencies. Before we move on to review these factors, it should be noted that the information provided below relates to either social and emotional competencies or intercultural competencies, since these are traditionally taught and researched separately. However, we argue that the vast majority of information valid for social and emotional competencies can generally be applied to intercultural competencies, and vice versa.

According to the CASEL guidelines for effective SEL programming, the successful implementation of SEL programmes requires that: I) programmes are theory- and research-based; 2) programmes apply learning to everyday situations and encourage children to use SEL skills in their daily life; 3) programmes build connections between students and their schools; 4) programmes are based on developmentally and culturally appropriate classroom instruction; 5) fragmentation of the programmes is avoided; 6) programmes encourage students' participation, positive interaction with teachers, and good study habits while enhancing students' performance by addressing the affective and social dimensions of academic learning; 7) programmes involve school staff, students, parents and community members in modelling SEL-related skills at home, at school and in the community; 8) high-quality programme implementation is secured by addressing key factors like leadership, adequate time and resources, and by including all stakeholders in SEL programming; 9) programmes offer professional development and support for all members of school staff; and io) programmes include a needs assessment to secure a good fit between the programme and school concerns and encourage data collection to ensure continuous programme improvement (CASEL, 2003; Fredericks, 2003). Many of these prerequisites were also recognised by in-service teachers. 
The following four factors were perceived to accelerate social and emotional learning: adopting schoolwide SEL programming instead of using fragmented approaches, embedding SEL in student learning standards, building teachers' capacity in SEL, and engaging parents and families (Bridgeland, Bruce and Hariharan, 2013). The need to incorporate SEL as an integral part of academics and the awareness of the ways in which diversity provides an ever-changing context for implementation of programmes are also outlined (Elias et al., 2003). The most distinctive factors seen as benefitting the development of intercultural competencies within the educational context are: strong leadership, staff training and support, effective role models, policies that promote intergroup relations, an emphasis on diversity across the curriculum, a diverse faculty and administration, and sensitivity to the local community (Cushner, 2004).

Several factors are acknowledged as hindering the success of social and emotional learning: the perpetuation of narrow and decontextualised programmes, poor management of resources, and negligence of the programme implementers' characteristics (Elias et al., 2003). Factors that hinder the development of intercultural competencies are: a lack of diversity among teachers and students, teachers' ethnocentrism, i.e. a lack of effective role models, non-democratic practices within the school, communities that are reluctant to change, and within-school segregation of majority and minority groups (Cushner, 2004).

Preferably, the quality of SEI programmes and the appropriateness of their implementation is assessed by an evaluative procedure aimed at investigating and improving their effects. In a systematic review focused on evaluating multicultural education programmes, i.e. programmes seeking to develop intercultural understanding and intercultural competencies, Stephan, Renfro and Stephan (2004) put forward possible tools and procedures for programme evaluations. We posit that these are equally useful for the evaluation of social and emotional learning programmes. The authors distinguish between quantitative and qualitative techniques for evaluating programmes. Quantitative designs that can be used to evaluate SEI programmes, going from most to least preferred, are the following: pre-test/post-test with a control group design, post-test only with a control group design, and pre-test/post-test with no control group design. Qualitative designs that Stephan et al. (2004) discuss are post-programme survey and observation, both being equally preferred, i.e. selected based on the programme characteristics and implementation circumstances. As the authors point out, "the better the design, the richer the inferences that can be drawn from the data. However, even the simplest evaluations can provide useful information regarding the effects of the program" 
(Stephan et al., 2004, p. 236). Nonetheless, evaluation seems to be omitted from many programme implementations, especially if they are tailored to schools vs. specialised training providers, e.g. agencies and universities (Stephan, 2004). This practice not only leads to the inability to identify areas for programme improvement, but also carries the risk of continuing the (often expensive) implementation of programmes that are ineffective, or worse, the persistence of those that might produce adverse effects.

Recent evidence corroborates the effectiveness of interventions adopting a whole-school approach to enhancing children and young people's social and emotional development (Goldberg et al., 2019). A meta-analysis of 45 studies demonstrated small yet significant improvements in students' social and emotional adjustment, behavioural adjustment and internalising symptoms, but no improvement in their academic achievement. The interventions that involved the community resulted in higher effect sizes compared to interventions without community involvement. Interventions conducted in the United States also appeared to have higher effect sizes than those conducted outside the USA (Goldberg et al., 2019). In their meta-analysis, Wigelsworth et al. (2016) arrived at three intriguing conclusions on the effectiveness of SEL: I) studies in which the developer has been identified as leading or being involved will show larger effect sizes in relation to independent studies; 2) studies implemented within the country of development will show larger effect sizes than those adopted and implemented outside the country of origin; and 3 ) studies coded as 'efficacy' will show larger effect sizes than those coded as 'effectiveness'. Namely, "whereas efficacy studies are typically conducted to demonstrate the efficacy and internal validity of a programme, effectiveness is used to test whether and how an intervention works in real-world contexts (...). Thus, a programme that demonstrates success at the efficacy stage may not yield similar results under real-world conditions" (Wigelsworth et al., 2016, p. 349; italics added).

Having in mind the preferred characteristics of SEL programmes (a wide range of content domains, long-term implementation, scientific evidence of effectiveness, on-site professional development to support quality implementation, schoolwide coordination, school-family partnerships, and school-community partnerships), CASEL experts commended three SEL programmes: Caring School Community; Promoting Alternative Thinking Strategies - PATHS; and Skills, Opportunities, and Recognition - SOAR (Weissberg et al., 2003).

Stephan et al. (2004) conducted a meta-analysis to determine if multicultural education programmes hold significant positive effects for attitudes and behaviours. On average, they revealed the positive effects of 
these programmes. The findings of the analysis strongly supported the contact hypothesis, stating that programmes which encompassed contact with target persons resulted in more positive behaviour change than programmes which did not include the contact (also see Lemmer and Wagner, 2015). They also found weak evidence elucidating that programmes containing experiential interventions had more positive outcomes than programmes which rely on less-involved techniques. A similar conclusion from Zhang and Zhou's (2019) study is that the effects of overseas immersion were superior to other types of (mainly pedagogical) interventions. Surprisingly, there was also some evidence in Stephan et al.'s (2004) work suggesting that group discussions hinder attitude and behaviour change since they can prove counter-productive if not closely monitored and moderated.

Additional insight into the effectiveness of programmes aimed at developing intercultural competencies comes from the study by Aboud et al. (2012). In their systematic review of the effects of interventions to reduce prejudice and enhance inclusion and respect for ethnic differences, they identified 32 studies that established inconclusive results (i.e. $40 \%$ positive, $50 \%$ non-significant and 10\% negative effects). Media and contact interventions proved to be somewhat more successful than instruction interventions. Stronger and more positive effects of interventions were found for attitudes compared to those for peer relations. Outcomes were more positive for majority than for minority ethnic children when attitudes, but not peer relations, were taken into account. The combination of factors that secured the highest percentage of positive effects was evident in the situation in which attitudes of majority children during contact were selected as the outcome variable (also see Lemmer and Wagner, 2015). The findings of Stephan et al. (2004) and Aboud et al. (2012) were greatly corroborated by those of Beelmann and Heinemann (2014) who conducted a meta-analysis of 122 comparisons of programmes to reduce prejudice or promote positive intergroup attitudes in children and adolescents. Overall, Beelmann and Heinemann (20I4) identified low to moderate intervention effects. Interventions focusing on direct contact experiences along with social-cognitive training aimed at promoting empathy and perspective-taking revealed the strongest effect sizes. Effects varied based on the group status (higher effects for majority groups), the target out-group (lower effect sizes for ethnic compared to disabled and elderly out-groups), and the type of assessment (higher effects for cognitive compared to affective and behavioural attitude measures).

In Stephan et al.'s (2004, p. 242) words: “A magic list of successful program components does not now and may never exist. It is likely that 
different types of programs can have positive, negative, or no effects, depending on the way in which they are implemented. It is imperative that program designers and implementers ascertain which outcomes their program produces". In conclusion, more regular, more precise and more rigorous assessment of the programmes is of the utmost importance (Jones et al., 2017; Paluck and Green, 2009). Indeed, the refinement of existing programmes is as important as the meticulous initial development of a programme's content, structure and design.

\section{Conclusion}

As the field of social and emotional learning has developed and grown over the last decades, so too has the number of different programmes seeking to achieve various SEL goals, resulting in a significant body of research on the topic. Meanwhile, there has also been an increase in the number of programmes aimed at developing intercultural competencies. For the purpose of developing a new programme for social and emotional learning, we reviewed the key characteristics of existing evidence-based social, emotional and intercultural learning programmes, including their theoretical and conceptual backgrounds, content, methodological and organisational aspects, and their evaluation. This review has revealed multiple similarities between these two approaches (i.e. social and emotional and intercultural), presenting a rationale for their integration.

A substantial body of evidence is now available for deriving conclusions on the general effectiveness of programmes for developing social and emotional as well as intercultural competencies. However, little is known about the possible synergistic effect of the concurrent implementation of the previously mostly separate endeavours to develop social, emotional and intercultural competencies. This seems to be a promising venue for future research.

When it comes to the theoretical background of existing SEI programmes, evidence suggests that the theoretical frameworks guiding their development tend to be fragmented and diverse. Yet, it seems that the CASEL conceptual framework (2003) offers a comprehensive basis for the programmes and their activities, as also reflected in its growing popularity and widespread utilisation. The theoretical/conceptual background is also closely tied with the programme content, resulting in a wide variety of different topics covered in the programmes under review, ranging from mental health promotion to prejudice reduction and the development of a multicultural school environment.

Reviewing the methodological and organisational aspects of existing SEI programmes also showed a variety of different approaches when 
it comes to programme implementation. Still, some conclusions may be drawn from this review, particularly with regard to programme setting and the involvement of school staff. The most (successful) programmes are usually school-based, and engage school staff, namely teachers, in their implementation. This implies that using existing resources in schools can go a long way to ensuring an overall better programme impact and long-lasting results, providing a good starting point for school-based social, emotional and intercultural learning.

\section{References}

Aboud, F. E., Tredoux, C., Tropp, L. R., Brown, C. S., Niens, U., and Noor, N. M. (2012) Interventions to reduce prejudice and enhance inclusion and respect for ethnic differences in early childhood: A systematic review. Developmental Review 32(4), pp. 307-336.

Allport, G. W. (1954) The nature of prejudice. Addison-Wesley.

Anderson, K. L., Weimer, M., and Fuhs, M. W. (2020) Teacher fidelity to Conscious Discipline and children's executive function skills. Early Childhood Research Quarterly, 51, pp. I4-25.

Auernheimer, G. (2003) Einführung in die Interkulturelle Pädagogik.

Darmstadt: Wissenschaftliche Buchgesellschaft.

Bandura, A., and Walters, R. H. (1977) Social learning theory (Vol. I). Englewood Cliffs, NJ: Prentice-hall.

Beelmann, A., and Heinemann, K. S. (2014) Preventing prejudice and improving intergroup attitudes: A meta-analysis of child and adolescent training programs. Journal of Applied Developmental Psychology 35(I), pp. 10-24.

Bennett, M. J. (2004) Becoming interculturally competent. In Wurzel, J. S. (ed.). Toward multiculturalism: a reader in multicultural education, pp. 62-77. Newton, MA: Intercultural Resource Corporation.

Berger, R., Benatov, J., Abu-Raiya, H., and Tadmor, C. T. (2016) Reducing prejudice and promoting positive intergroup attitudes among elementary-school children in the context of the Israeli-Palestinian conflict. Journal of School Psychology, 57, pp. 53-72.

Berger, R., Brenick, A., and Tarrasch, R. (2018) Reducing Israeli-Jewish pupils' outgroup prejudice with a mindfulness and compassion-based social-emotional program. Mindfulness 9, pp. 1768-1779.

Berry, V., Axford, N., Blower, S., Taylor, R. S., Tudor Edwards, R., Tobin, K., Jones, C., and Bywater, T. (2016) The effectiveness and micro-costing analysis of a universal, school-based, social-emotional learning 
programme in the UK: A cluster-randomised controlled trial. School Mental Health 8, pp. 238-256.

Bourdieu, P. (1984) Distinction: A social critique of the judgement of taste. London: Routledge.

Brackett, M. A., Elbertson, N. A., and Rivers, S. E. (2015) Applying theory to the development of approaches to social and emotional learning. In Durlak, J. A., Domitrovic, C. E., Weissberg, R. P., and Gullotta, T. P. (eds.). Handbook of social and emotional learning: Research and practice, pp. 20-32. New York: Guilford Press.

Bridgeland, J., Bruce, M., and Hariharan, A. (2013) The missing piece: A national teacher survey on how social and emotional learning can empower children and transform schools. A report for CASEL. Civic Enterprises.

CASEL (2003) Safe and sound: An educational leader's guide to evidence-based social and emotional learning programs. Chicago: Collaborative for Academic, Social, and Emotional Learning.

Catalano, R. F., Berglund, M. L., Ryan, J. A., Lonczak, H. S., and Hawkins, J. D. (2002) Positive youth development in the United States: Research findings on evaluations of positive youth development programs. Prevention \& Treatment 5(I), isa.

Coelho, V., Sousal, V., Raimundo, R., and Figueira, A. (2017) The impact of a Portuguese middle school social-emotional learning program. Health Promotion International 32, pp. 292-300.

Coie, J. D., Watt, N. F., West, S. G., Hawkins, J. D., Asarnow, J. R., Markman, J. H., et al. (1993). The science of prevention: A conceptual framework and some directions for a national research program. American Psychologist 48, pp. IO13-1022.

Cook, T. D., Habib, F. N., Phillips, M., Settersten, R. A., Shagle, S. C., and Degirmencioglu, S. M. (1999) Comer's school development program in Prince George's County, Maryland: A theory-based evaluation. American Educational Research Journal 36(3), pp. 543-597.

Cowen, E. L. (1983) Primary prevention in mental health: Past, present, and future. In Felner, R. D., Jason, L. A., Moritsugu, J. N., ad Farber, S. S. (eds.). Preventive psychology: Theory, research and practice, pp. II-25. New York: Pergamon Press.

Cushner, K. (2004) Conditions in the organizational environment that support positive intergroup relations. In Stephan, W. G., and Vogt, W. P. (eds.). Education programs for improving intergroup relations: Theory, research, and practice, pp. 2II-226. New York: Teachers College Press. 
Di Bernardo, G. A., Vezzali, L., Stathi, S., Cadamuro, A., and Cortesi, L. (2017) Vicarious, extended and imagined intergroup contact: A review of interventions based on indirect contact strategies applied in educational settings. TPM-Testing, Psychometrics, Methodology in Applied Psychology 24(I), pp. 3-2I.

Durlak, J. A., Weissberg, R. P., Dymnicki, A. B., Taylor, R. D., and Schellinger, K. B. (2011) The impact of enhancing students' social and emotional learning: A metaanalysis of schoolbased universal interventions. Child Development 82(I), pp. 405-432.

Elias, M. J., Zins, J. E., Graczyk, P. A., and Weissberg, R. P. (2003)

Implementation, sustainability, and scaling up of social-emotional and academic innovations in public schools. School Psychology Review 32(3), pp. 303-319.

Elias, M. J., Zins, J. E., Weissberg, R.P., Frey, K.S., Greenberg, M.T., Haynes, N.M., Kessler, R., Schwab-Stone, M.E., and Shriver, T.P. (1997) Promoting social and emotional learning: Guidelines for educators. ASCD.

Fredericks, L. (2003) Making the case for social and emotional learning and service-learning. ECS issue brief. Education Commission of the States $(\mathrm{NJ} \mathrm{I})$.

Garner, P. W., Mahatmya, D., Brown, E. L., and Vesely, C. K. (20I 4) Promoting desirable outcomes among culturally and ethnically diverse children in social emotional learning programs: A multilevel heuristic model. Educational Psychology Review 26(I), pp. 165-I89.

Glantz, M. D., and Johnson, J. L. (eds.). (1999) Resilience and development: Positive life adaptations. New York: Kluwer Academic/Plenum.

Goldberg, J. M., Sklad, M., Elfrink, T. R., Schreurs, K. M., Bohlmeijer, E. T., and Clarke, A. M. (2019) Effectiveness of interventions adopting a whole school approach to enhancing social and emotional development: A meta-analysis. European Journal of Psychology of Education 34(4), pp. 755-782.

Greenberg, M. T., Weissberg, R. P., O’Brien, M. U., Zins, J. E., Fredericks, L., Resnik, H., and Elias, M. J. (2003) Enhancing school-based prevention and youth development through coordinated social, emotional, and academic learning. American psychologist 58(6-7), pp. 466-474.

Gueldner, B. A., and Feuerborn, L. L. (2016) Integrating mindfulness-based practices into social and emotional learning: A case application. Mindfulness 7(I), pp. 164-175. 
Gundara, J. S. (2000) Interculturalism, education and inclusion. London: Paul Chapman Publishing.

Hernández-Bravo, J.A., Cardona-Moltó, M.C., and Hernández-Bravo, J.R. (2017) Developing elementary school students' intercultural competence through teacher-led tutoring action plans on intercultural education. Intercultural Education 28(I), pp. 20-38.

Hetherington, M. (ed.). (1998) Applications of developmental science [Special issue]. American Psychologist, 53(2).

Jones, S. M., Barnes, S. P., Bailey, R., and Doolittle, E. J. (2017) Promoting social and emotional competencies in elementary school. The Future of Children, pp. 49-72.

Jugović, I., Puzić, S., and Mornar, M. (2020) Development of the social, emotional and intercultural learning programme for students. In Kozina, A. (ed.). Social, emotional and intercultural competencies for inclusive school environments across Europe, pp. 59-82. Berlin: Verlag Dr. Kovač.

Katunarić, V. (1994) Labirint evolucije. Zagreb: Zavod za sociologiju Filozofskog fakulteta.

Kelly, B., Longbottom, J., Potts, F., and Williamson, J. (2004) Applying emotional intelligence: Exploring the promoting alternative thinking strategies curriculum. Educational Psychology in Practice 20(3), pp. 22I-240.

Ladd, G. W., and Mize, J. (1983) A cognitive-social learning model of social-skill training. Psychological Review 90(2), pp. 127-157.

Larson, R. W. (2000) Toward a positive psychology of youth development. American Psychologist 55, pp. 170-183.

Leiprecht, R. (200I) Förderung interkultureller und antirassistischer Kompetenz. In Leiprecht, R., Riegel, C., Held, J., and Wiemeyer, G. (eds.). International Lernen - Lokal Handeln, pp. 17-46. Frankfurt a. M.: IKO.

Lemmer, G., and Wagner, U. (2015) Can we really reduce ethnic prejudice outside the lab? A meta-analysis of direct and indirect contact interventions. European Journal of Social Psychology 45(2), pp. 152-168.

Lerner, R. M., Fisher, C. B., and Weinberg, R. A. (2000) Toward a science for and of the people: Promoting civil society through the application of developmental science. Child Development 7I, pp. II-20.

Liebkind, K., Mähönen, T. A., Solares, E., Solheim, E., and JasinskajaLahti, I. (2014) Prejudice-reduction in culturally mixed classrooms: The development and assessment of a theory-driven 
intervention among majority and minority youth in Finland. Journal of Community \& Applied Social Psychology 24(4), pp. 325-339.

Luchtenberg, S. (2005) Multicultural education: Challenges and responses. Journal for Social Science Education 4, pp. 31-55.

Marušić, I., Jugović, I., Puzić, S., Matić, J., Košutić, I., Kozina, A., Veldin, M., Sälzer, C., Eliasson, N., Lund Nielsen, B., Vieluf, S., Ojsteršek, A., and Jurko, L. (2017) SEI Programmes for Students: A Review Catalogue. Retrieved from: http://handinhand.si (is July 2020).

Marušić, I., Puzić, S., Jugović, I., Košutić, I., Matić, J., Mornar, M., Nielsen, B. L., Jensen, H., Rasmusson, M., Oskarsson, M., Denk, A., Kozina, A., and Veldin, M. (2020) HAND in HAND program for students, manual. Retrieved from: http://handinhand.si (is July 2020).

Marx, E., and Wooley, S. F., with Northrop, D. (eds.) (1998) Health is academic: A guide to coordinated health programs. New York: Teachers College Press.

Masten, A. S., and Coatsworth, J. D. (1998) The development of competence in favorable and unfavorable environments: Lessons from research on successful children. American Psychologist 53, pp. 205-220.

McCormick, M. P., Cappella, E., O’Connor, E. E., and McClowry, S. G. (2015) Context matters for social-emotional learning: Examining variation in program impact by dimensions of school climate. American Journal of Community Psychology 56(I-2), Pp. IOI-II9.

Mendelson, T., Greenberg, M. T., Dariotis, J. K., Gould, L. F., Rhoades, B. L., and Leaf, P. J. (2о10) Feasibility and preliminary outcomes of a school-based mindfulness intervention for urban youth. Journal of $a b$ normal child psychology 38(7), pp. 985-994.

Mrazek, P. J., and Haggerty, R. J. (eds.). (1994) Reducing risks for mental disorders: Frontiers for preventive intervention research. Washington, DC: National Academy Press.

Paluck, E. L., and Green, D. P. (2009) Prejudice reduction: What works? A review and assessment of research and practice. Annual Review of Psychology 60, pp. 339-367.

Payton, J. W., Wardlaw, D. M., Graczyk, P. A., Bloodworth, M. R., Tompsett, C. J., and Weissberg, R. P. (2000) Social and emotional learning: A framework for promoting mental health and reducing risk behavior in children and youth. Journal of School Health $70(5)$, pp. 179-185.

Perry, C. L. (1999) Creating health behavior change: How to develop community-wide programs for youth. Thousand Oaks, CA: Sage. 
Pettigrew, T. F., Tropp, L. R., Wagner, U., and Christ, O. (2011) Recent advances in intergroup contact theory. International Journal of Intercultural Relations 35(3), pp. 271-280.

Pittman, K. J., Irby, M., Tolman, J., Yohalem, N., and Ferber, T. (200I) Preventing problems, promoting development, encouraging engagement: Competing priorities or inseparable goals? Retrieved from: http://www. forumforyouthinvestment.org/preventproblems.pdf (is July 2020).

Raabe, T., and Beelmann, A. (2011) Development of ethnic, racial, and national prejudice in childhood and adolescence: A multinational meta-analysis of age differences. Child development 82(6), pp. 1715-1737.

Reiss, D., and Price, R. H. (1996) National research agenda for prevention research: The National Institute of Mental Health report. American Psychologist, 51, pp. IIO9-III5.

Schonert-Reichl, K. A., and Lawlor, M. S. (2010) The effects of a mindfulness-based education program on pre-and early adolescents' well-being and social and emotional competence. Mindfulness I(3), pp. 137-15I.

Schonert-Reichl, K. A., Oberle, E., Lawlor, M. S., Abbott, D., Thomson, K., Oberlander, T. F., and Diamond, A. (2015) Enhancing cognitive and social-emotional development through a simple-to-administer mindfulness-based school program for elementary school children: A randomized controlled trial. Developmental Psychology 5I(I), 52.

Seligman, M. E. P., and Csikszentmihalyi, M. (eds.) (2000) Special issue on happiness, excellence, and optimal human functioning. American Psychologist 55(I).

Sklad, M., Diekstra, R., Ritter, M. D., Ben, J., and Gravesteijn, C. (2012) Effectiveness of school-based universal social, emotional, and behavioral programs: Do they enhance students' development in the area of skill, behavior, and adjustment?. Psychology in the Schools 49(9), pp. 892-909.

Stephan, C. W. (2004) Conclusion: Understanding Intergroup Relations Programs. In Stephan, W. G., and Vogt, W. P. (eds.) Education programs for improving intergroup relations: Theory, research, and practice, pp. 266-279. New York: Teachers College Press.

Stephan, C. W., Renfro, L., and Stephan, W. G. (2004) The evaluation of intergroup relations programs: Techniques and a meta-analysis. Learning together: Intergroup relations programs.

Taylor, R. D., Oberle, E., Durlak, J. A., and Weissberg, R. P. (2017) Promoting positive youth development through school based social and emotional learning interventions: A metaanalysis of followup effects. Child Development 88(4), pp. II56-II7I. 
Walton, J., Priest, N., and Paradies, Y. (2013) Identifying and developing effective approaches to foster intercultural understanding in schools. Intercultural Education, 24(3), pp. I8I-194.

Weissberg, R. P., Durlak, J. A., Domitrovich, C. E., and Gullotta, T. P. (2015) Handbook of social and emotional learning: Research and practice. New York: Guildford Press.

Weissberg, R. P., and Greenberg, M. T. (1998) School and community competence-enhancement and prevention programs. In Damon, W. (Series ed.) and Sigel, I. E. and Renninger, K. A. (Vol. eds.). Handbook of child psychology: Vol. 4. Child psychology in practice (sth ed), pp. 877-954. New York: Wiley.

Weissberg, R. P., Kumpfer, K. L., and Seligman, M. E. (2003) Prevention that works for children and youth: An introduction. American Psychological Association 58 (6-7), p. 425.

Weissberg, R. P., Resnik, H., Payton, J., and O Brien, M. U. (2003) Evaluating social and emotional learning programs. Educational Leadership 6o(6), pp. 46-50.

Wigelsworth, M., Lendrum, A., Oldfield, J., Scott, A., ten Bokkel, I., Tate, K., and Emery, C. (2016) The impact of trial stage, developer involvement and international transferability on universal social and emotional learning programme outcomes: A meta-analysis. Cambridge Journal of Education 46(3), pp. 347-376.

Yamamoto, T., Matsumoto, Y., and Bernard, M. E. (2017) Effects of the cognitive-behavioral you can do it! Education program on the resilience of Japanese elementary school students: a preliminary investigation. International Journal of Educational Research 86, pp. 50-58.

Yeager, D. S. (2017) Social and emotional learning programs for adolescents. The Future of Children, pp. 73-94.

Zhang, X., and Zhou, M. (2019) Interventions to promote learners' intercultural competence: A meta-analysis. International Journal of Intercultural Relations 7I, pp. 3I-47.

Zins, J. E., and Elias, M. J. (2006) Social and emotional learning. Children's needs III: Development, prevention, and intervention, pp. I-I3.

Zirkel, S. (2008) The influence of multicultural educational practices on student outcomes and intergroup relations. Teachers College Record IIo(6), pp. II 47-II8I. 